\title{
Correction: Sagar et al. Forest Restoration at Berenty Reserve, Southern Madagascar: A Pilot Study of Tree Growth Following the Framework Species Method. Land 2021, 10, 1041
}

\author{
Rubin Sagar ${ }^{1}$, Ariadna Mondragon-Botero ${ }^{2}$, Francine Dolins ${ }^{3} \mathbb{D}$, Bryn Morgan ${ }^{4}$, Thuy Phuong Vu 4 , \\ Janet McCrae ${ }^{5}$ and Vanessa Winchester ${ }^{6, * \text { (D) }}$
}

Citation: Sagar, R.;

Mondragon-Botero, A.; Dolins, F.;

Morgan, B.; Vu, T.P.; McCrae, J.;

Winchester, V. Correction: Sagar et al. Forest Restoration at Berenty Reserve, Southern Madagascar: A Pilot Study of Tree Growth Following the Framework Species Method. Land 2021, 10, 1041. Land 2022, 11, 332. https://doi.org/10.3390/ land11030332

Received: 10 January 2022 Accepted: 11 January 2022

Published: 24 February 2022

Publisher's Note: MDPI stays neutral with regard to jurisdictional claims in published maps and institutional affiliations.

Copyright: (C) 2022 by the authors. Licensee MDPI, Basel, Switzerland. This article is an open access article distributed under the terms and conditions of the Creative Commons Attribution (CC BY) license (https:// creativecommons.org/licenses/by/ $4.0 /)$.

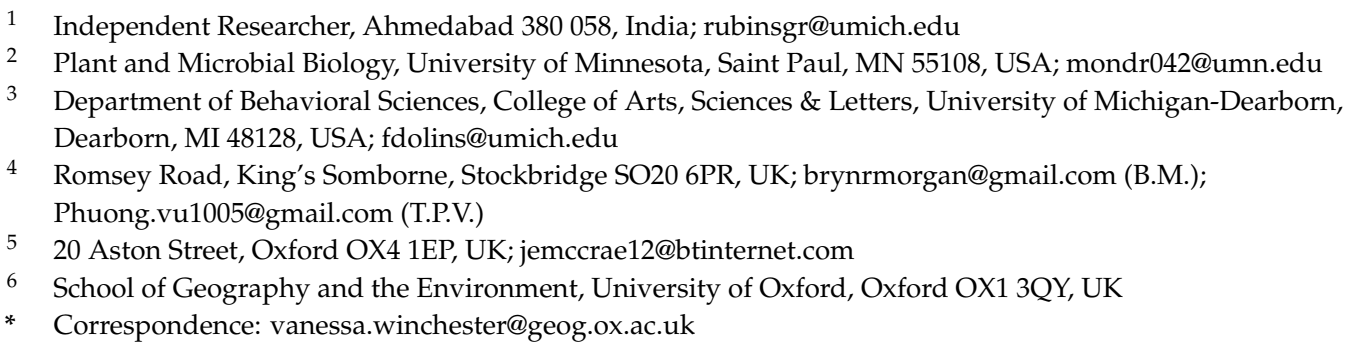

\section{Correct Email Address}

In the published publication [1], there was an error regarding the email address for Bryn Morgan. The correct email address should be brynrmorgan@gmail.com. The authors apologize for any inconvenience caused and state that the scientific conclusions are unaffected. The original publication has also been updated.

\section{Text Correction}

The authors would like to correct the following section of this paper [1]:

Incorrect Content

There was an error in the original publication. The correct year in paragraph 4 should not be "1973" but "1980". The authors apologize for any inconvenience caused, and state that the scientific conclusions are unaffected.

Wrong:

Berenty is a prime example of environmental conservation in a region that is otherwise suffering deforestation at an unprecedented rate [14]. The Reserve has been owned and protected by the de Heaulme family since 1936, but as early as 1973 primatologists noticed that the forest was shrinking and degrading $[15,16]$. It was clear that reasons for increasing degradation needed investigation [17].

Right:

Berenty is a prime example of environmental conservation in a region that is otherwise suffering deforestation at an unprecedented rate [14]. The Reserve has been owned and protected by the de Heaulme family since 1936, but as early as 1980 primatologists noticed that the forest was shrinking and degrading $[15,16]$. It was clear that reasons for increasing degradation needed investigation [17].

\section{Reference}

1. Sagar, R.; Mondragon-Botero, A.; Dolins, F.; Morgan, B.; Vu, T.P.; McCrae, J.; Winchester, V. Forest Restoration at Berenty Reserve, Southern Madagascar: A Pilot Study of Tree Growth Following the Framework Species Method. Land 2021, 10, 1041. [CrossRef] 